\title{
Evaluation of protein adsorption to diamond-like carbon (DLC) and fluorine- doped DLC films using the quartz crystal microbalance method
}

\author{
Haruka ISHIGE ${ }^{1}$, Shun AKAIKE¹, Tohru HAYAKAWA², Masanori HIRATSUKA ${ }^{3}$ and Yoshiki NAKAMURA ${ }^{1}$ \\ ${ }^{1}$ Department of Orthodontics, Tsurumi University School of Dental Medicine, 2-1-3 Tsurumi, Tsurumi-ku, Yokohama 230-8501, Japan \\ ${ }^{2}$ Department of Dental Engineering, Tsurumi University School of Dental Medicine, 2-1-3 Tsurumi, Tsurumi-ku, Yokohama 230-8501, Japan \\ ${ }^{3}$ Nanotec Corporation, 572-61 Toyofuta, Kashiwa City, Chiba 277-0872, Japan \\ Corresponding author, Haruka ISHIGE; E-mail: h_i_1831008@yahoo.co.jp
}

\begin{abstract}
The aim of the present study was to evaluate albumin adsorption to stainless steel (SUS), diamond-like carbon (DLC) and fluorinedoped DLC (F-DLC) films using the quartz crystal microbalance (QCM) method. Each sensor was characterized using atomic force microscopy, surface roughness and surface wettability measurements and surface free energy calculations. Adsorbed amounts of bovine serum albumin on DLC and F-DLC were significantly lower than that on SUS $(p<0.05)$. The apparent first-order reaction rate, $k_{\mathrm{obs}}$, of F-DLC was significantly larger than those of SUS and DLC $(p<0.05)$. Moreover, significantly lower total surface free energies of DLC and F-DLC influenced the albumin absorbed amounts and $k_{\mathrm{obs}}$. Furthermore, a clear correlation was found between the albumin absorbed amounts and the hydrogen bond component of the total surface free energy. Thus, DLC or F-DLC coating is effective for preventing protein adsorption on orthodontic appliances.
\end{abstract}

Keywords: Diamond-like carbon, Albumin adsorption, Quartz crystal microbalance, Contact angle, Surface free energy

\section{INTRODUCTION}

In orthodontics, orthodontic brackets and wires are commonly used to treat malocclusion. An important factor influencing tooth movement is static friction that is present between brackets and wires. Lower friction enhances effective tooth movement due to more efficient force transmission to the teeth, which can allow the treatment period to be shortened without undesirable anchorage loss or pain to the patient $t^{1,2)}$. Numerous studies regarding the reduction of the friction between brackets and wires have been reported ${ }^{1,3,4)}$.

Recently, diamond-like carbon (DLC) has been used in various industrial applications ${ }^{5}$ because of its excellent physical properties, such as extreme surface hardness, low friction coefficient, chemical inertness, high wear resistance and superior biocompatibility ${ }^{6,7)}$. In orthodontics, application of DLC coating on brackets and wires has been reported to reduce the friction between the bracket and wire ${ }^{8,9}$. Previously, we reported that homogeneous DLC-coated orthodontic brackets significantly reduced static friction between brackets and wires under both dry and wet conditions ${ }^{10}$. Moreover, fluorine-doped DLC (F-DLC) and silicon-doped DLC (Si-DLC) coatings were deposited onto brackets and frictional properties between coated brackets and wires under dry and wet conditions were characterized ${ }^{11}$. DLC, F-DLC and Si-DLC coatings provided a significant reduction in static friction, and F-DLC-coated brackets exhibited the significantly lowest static friction between the bracket and wire under wet conditions, which was lower than that under dry conditions, among the three

Color figures can be viewed in the online issue, which is available at J-STAGE.

Received Feb 20, 2018: Accepted Sep 6, 2018

doi:10.4012/dmj.2018-060 JOI JST.JSTAGE/dmj/2018-060 tested coatings.

Orthodontic appliances used in the oral cavity are continually exposed to salivary proteins and oral bacteria. Friction increases and orthodontic brackets and wires deteriorate in the oral environment because of protein adsorption, which subsequently leads to an acquired pellicle and plaque formation on the orthodontic appliance ${ }^{12-15)}$. Furthermore, it is presumed that salivary protein adsorption or adhesion is the initial stage of biofilm formation ${ }^{16,17)}$. Therefore, orthodontic appliances that are resistant to protein adsorption are desirable. However, evaluation of oral protein adsorption on DLC and F-DLC films has not yet been conducted.

Several methods are used to analyze protein adsorption, such as infrared reflection spectroscopy, ellipsometry and surface plasmon resonance ${ }^{18}$. Among them, the quartz crystal microbalance (QCM) technique is a straightforward method for detecting protein adsorption onto a material surface by measuring differences in the oscillating frequency of the quartz cell ${ }^{19}$. When molecules bind to the oscillating quartz crystal, the oscillating frequency decreases in relation to the amount of protein bound to the crystal surface. Yoshida and Hayakawa evaluated the adsorption of pellicle proteins to dental materials by the $\mathrm{QCM}$ method $^{20,21)}$. They found that the adsorption behavior of pellicle proteins were influenced by the kinds of proteins and materials.

The aim of the present study was to evaluate protein adsorption to stainless steel (SUS)-, DLC- and F-DLCcoated surfaces using the QCM method. Albumin is a major component of oral saliva. Thus, the adsorption of albumin was evaluated. The influence of surface free energy on albumin adhesion was mainly analyzed. 
The null hypothesis of the present study was that the different surfaces, namely, SUS, DLC and F-DLC, do not influence albumin adsorption.

\section{MATERIALS AND METHODS}

\section{Sample preparation}

$\mathrm{Au}$ sensors for QCM measurements were coated with stainless steel 304 (SUS), DLC or F-DLC (Table 1). The SUS sensor was prepared by sputter coating (CS200, ULVAC, Kanagawa, Japan) with the use of a SUS 304 target. Each DLC coating was performed by the direct current-pulsed plasma-enhanced chemical vapor deposition method (DC-pulsed PECVD; NPS330, Nanotec, Chiba, Japan ${ }^{11}$. The source gas for DLC and F-DLC coating was $\mathrm{C}_{2} \mathrm{H}_{2}$ and $\mathrm{C}_{6} \mathrm{~F}_{6}$, respectively, and the base substrate under DLC and F-DLC layers is gold. During the coating process, the source gas was dissociated and ionized by plasma discharge. The resulting positively charged ions were attracted to the negatively biased substrate. The thickness of SUS, DLC and F-DLC demined by stylus profilemeter (Dektak150, Bruker Nano, for SUS, SURFCOM E-RM-S01A, Tokyo Seimitsu for DLC and F-DLC) was 150, 20-30 and 20$30 \mu \mathrm{m}$, respectively.

\section{Surface characterization}

Atomic force microscopy (AFM; Nanosurf Easyscan 2, Nanosurf, Liestal, Switzerland) observation was performed to identify the surface morphology and surface roughness of each sensor. AFM images were captured in air by the tapping mode. Tapping mode silicon probes (Tap190AL-G, force contact $48 \mathrm{~N} / \mathrm{m}$; BudgetSensors, Sofia, Bulgaria) with resonance frequencies of approximately $190 \mathrm{kHz}$ were used for imaging. AFM images were obtained in an area measuring $5 \times 5 \mu \mathrm{m}^{2}$. Surface roughness (arithmetic mean height) was calculated using software (Nanosurf Easyscan 2) supplied with the AFM. All measurements were performed three times.

The surface wettability of each sensor surface was measured using a contact angle meter (DMe-201, Kyowa Interface Science, Tokyo, Japan), and surface free energies were obtained by measuring the contact angle with double-distilled water (WCA) and diiodomethane (DCA). Each sensor was irradiated by ultraviolet radiation (UV ozone cleaner, BioForce Nanosciences Holdings, Ames, IA, USA) for 20 min before contact angle measurement. The liquid drop volume was maintained at $0.5 \mu \mathrm{L}$. Measurements were performed three times at the same room temperature and humidity.

The total surface free energy $\left(\gamma^{\text {total }}\right)$, as well as dispersive surface $\left(\gamma^{\mathrm{d}}\right)$ and hydrogen bond $\left(\gamma^{\mathrm{h}}\right)$ components, were calculated by the Owens-Wendt theory according to the following equation ${ }^{22-24)}$ :

$$
\gamma_{\mathrm{L}}(1+\cos \theta)=2\left(\sqrt{\gamma_{\mathrm{L}}^{\mathrm{d}} \gamma_{\mathrm{S}}^{\mathrm{d}}}+\sqrt{\gamma_{\mathrm{L}}^{\mathrm{p}} \gamma_{\mathrm{S}}^{\mathrm{p}}}\right)
$$

where $\gamma_{L}$ and $\gamma_{S}$ are liquid surface tension and solid surface energy, respectively, $\gamma^{\mathrm{d}}$ of water and diiodomethane are 21.8 and $49.5 \mathrm{mN} / \mathrm{m}$ and $\gamma^{\mathrm{h}}$ of water and diiodomethane are 51 and $1.3 \mathrm{mN} / \mathrm{m}$, respectively ${ }^{22-25}$.

\section{QCM measurements}

A 27-MHz QCM (AT-cut shear mode; AFFINIX QN $\mu$, ULVAC) with a $500-\mu \mathrm{L}$ sensor cell was used ${ }^{26}$. The sensor cell of each sensor was mounted in the cell socket of the QCM apparatus. The temperature control system and stir bar were then equipped. The temperature was maintained at $25 \pm 1^{\circ} \mathrm{C}$ and the solution in the cell was stirred at 1,000 rpm during the measurement.

Bovine serum albumin (BSA; Wako Pure Chemical Industries, Osaka, Japan) was dissolved in a phosphatebuffered saline (PBS) solution $(\mathrm{pH}=7.4)$ at a concentration of $1 \mathrm{mg} / \mathrm{mL}$. Before mounting the sensor cell, each sensor was cleaned with a $1 \%$ sodium dodecyl sulfate solution and then irradiated with ultraviolet light (BioForce Nanosciences Holdings) for $20 \mathrm{~min}$. After mounting the sensor cell, $500 \mu \mathrm{L}$ of PBS was added to the cell. After stabilization of the frequency shift, $1 \mathrm{mg} / \mathrm{mL}$ BSA solution $(0.5 \mu \mathrm{L})$ was injected into the PBS solution in the cell. The frequency decrease was monitored until 120 min after BSA injection.

The albumin adsorbed amount at 120 min after BSA injection was calculated as follows by the Sauerbrey equation $^{27)}$ :

$$
\Delta F=-\frac{2 F_{0}^{2} \Delta m}{\mathrm{~A} \sqrt{\rho_{q} \mu_{q}}}
$$

where $\Delta F$ is the measured frequency shift $(\mathrm{Hz}), \Delta m$ is the mass change $(\mathrm{g}), F_{0}$ is the fundamental frequency of the quartz crystal $\left(27 \times 10^{6} \mathrm{~Hz}\right), A$ is the electrode area $\left(0.049 \mathrm{~cm}^{2}\right), \rho_{q}$ is the density of quartz $\left(2.65 \mathrm{gcm}^{-3}\right)$ and $\mu_{q}$ is the shear modulus of quartz $\left(2.95 \times 10^{11} \mathrm{dyncm}^{-2}\right)$. At $27 \mathrm{MHz}$, a frequency decrease of $1 \mathrm{~Hz}$ corresponds to a mass change of approximately $0.62 \mathrm{ng} / \mathrm{cm}^{2}$ according to the Sauerbrey equation ${ }^{27}$. By curve fitting for the $\Delta F$ curve against the adsorption time, the apparent reaction rate, $k_{\mathrm{obs}}$, during $10 \mathrm{~min}$ of injection, was obtained using

Table 1 Sensors for QCM measurements

\begin{tabular}{ccl}
\hline Sensor & Target/source gas & \\
\hline SUS & SUS 304 & sputter coating \\
DLC & $\mathrm{C}_{2} \mathrm{H}_{2}$ & DC-pulsed PECVC \\
F-DLC & $\mathrm{C}_{6} \mathrm{~F}_{6}$ & DC-pulsed PECVC \\
\hline
\end{tabular}


the following equation:

$$
\Delta F_{t}=\Delta F_{\infty}\left(1-e^{-k_{\mathrm{obs}} \cdot t}\right)
$$

where $\Delta F_{\infty}$ is the frequency shift at infinite time. Three runs of QCM measurements for protein adsorption to each sensor were performed that each lasted $120 \mathrm{~min}$.

After QCM measurements, AFM images of each sensor were also observed as described above.

\section{Statistical analysis}

Statistical analyses were performed using SPSS (version 16.0J for Windows, IBM Japan, Tokyo, Japan) software. The mean and standard deviation (SD) of surface roughness, contact angle, surface free energy and QCM data were calculated. The results for each sensor were compared using a one-way analysis of variance (ANOVA) and Tukey's tests, with $p<0.05$ considered to indicate statistical significance.

\section{RESULTS}

\section{Surface characterization}

Needle-like images were observed on the SUS surface and spherical particles were observed on DLC and F-DLC surfaces by AFM observation (Fig. 1). There were significant differences in surface roughness between SUS and DLC $(p<0.05)$ and SUS and F-DLC $(p<0.05)$
(Table 2). However, no significant difference in surface roughness was observed between DLC and F-DLC $(p>0.05)$.

The results of contact angle measurements and the calculation of surface free energies are shown in Tables 3 and 4, respectively. There were significant differences in the WCA among the three surface types $(p<0.05)$. However, for the DCA, no significant difference was observed between SUS and DLC $(p>0.05)$. F-DLC showed significantly greater WCA and DCA values than SUS and DLC $(p<0.05)$.

Regarding the dispersive surface component $\left(\gamma^{\mathrm{d}}\right)$, DLC showed significantly greater values than SUS $(p<0.05)$, and F-DLC showed significantly smaller values than DLC $(p<0.05$, Table 4$)$. There was a significant decrease in the hydrogen bond surface component $\left(\gamma^{\mathrm{h}}\right)$ of DLC and F-DLC compared with that of SUS $(p>0.05)$. Moreover, total surface free energies $\left(\gamma^{\text {total }}\right)$ of DLC and F-DL were significantly smaller than that of SUS $(p>0.05)$.

\section{QCM measurements}

A frequency decrease was observed after albumin injection. As shown in Fig. 2, SUS exhibited a more rapid and greater frequency decrease than DLC and F-DLC. The calculated BSA absorbed amounts are listed in Table 5. The BSA absorbed amounts on DLC and F-DLC were significantly lower than that on SUS $(p<0.05)$. However, there was no significant difference in BSA absorbed
SUS
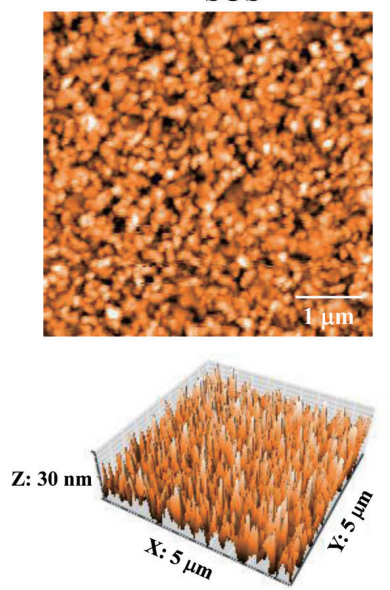

DLC
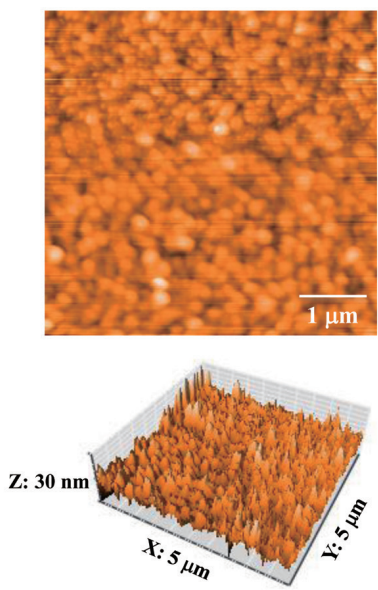

F-DLC
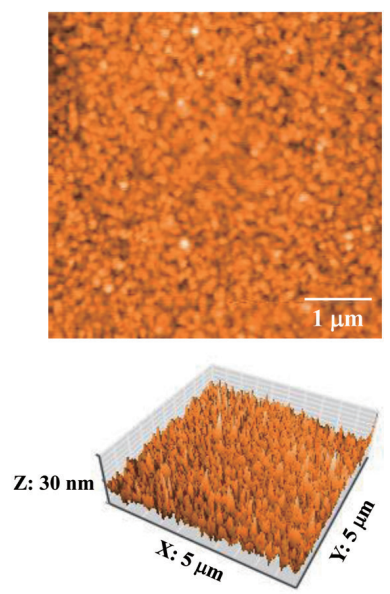

Fig. 1 AFM images of (a) SUS-, (b) DLC- and (c) F-DLC-coated QCM sensors.

Table 2 Surface roughness (Sa) of each sensor

\begin{tabular}{ll}
\hline Sensor & Sa $(\mathrm{nm})$ \\
\hline SUS & $4.38(0.18)^{\mathrm{a}}$ \\
DLC & $3.02(0.39)^{\mathrm{b}}$ \\
F-DLC & $2.48(0.29)^{\mathrm{b}}$ \\
\hline
\end{tabular}

Data are expressed as means (SD).

Groups that do not share the same superscript letter are significantly different $(p<0.05)$. 
Table 3 Water and diiodomethane contact angles of each sensor

\begin{tabular}{lcc}
\hline Sensor & Water contact angle $\left(^{\circ}\right)$ & Diiodomethane contact angle $\left(^{\circ}\right)$ \\
\hline SUS & $54.3(3.7)^{\mathrm{a}}$ & $39.6(1.0)^{\mathrm{a}}$ \\
DLC & $71.9(2.7)^{\mathrm{b}}$ & $34.8(2.2)^{\mathrm{a}}$ \\
F-DLC & $87.7(1.7)^{\mathrm{c}}$ & $51.0(2.2)^{\mathrm{b}}$ \\
\hline
\end{tabular}

Data are expressed as means (SD).

Groups that do not share the same superscript letter are significantly different $(p<0.05)$.

Table 4 Dispersive surface component, hydrogen bond surface component and total surface free energy of each sensor

\begin{tabular}{cccc}
\hline Sensor & $\begin{array}{c}\text { Dispersive surface component } \\
(\mathrm{mN} / \mathrm{m})\end{array}$ & $\begin{array}{c}\text { Hydrogen bond surface } \\
\text { component }(\mathrm{mN} / \mathrm{m})\end{array}$ & $\begin{array}{c}\text { Total surface free energy } \\
(\mathrm{mN} / \mathrm{m})\end{array}$ \\
\hline SUS & $32.5(1.8)^{\mathrm{a}}$ & $19.0(3.2)^{\mathrm{a}}$ & $51.4(1.5)^{\mathrm{a}}$ \\
DLC & $37.9(0.3)^{\mathrm{b}}$ & $5.9(0.8)^{\mathrm{b}}$ & $43.8(0.6)^{\mathrm{b}}$ \\
F-DLC & $28.7(2.4)^{\mathrm{a}}$ & $3.3(1.1)^{\mathrm{b}}$ & $32.0(1.3)^{\mathrm{c}}$ \\
\hline
\end{tabular}

Data are expressed as means (SD).

Groups that do not share the same superscript letter are significantly different $(p<0.05)$.

Table 5 Albumin absorption amounts and $k_{\text {obs }}$ of each sensor

\begin{tabular}{lcc}
\hline Sensor & Albumin adsorption amounts $\left(\mathrm{ng} / \mathrm{cm}^{2}\right)$ & $k_{\text {obs }}\left(\times 10^{3}\right)$ \\
\hline SUS & $621.2(62.0)^{\mathrm{a}}$ & $2.2(0.6)^{\mathrm{a}}$ \\
DLC & $461.2(35.1)^{\mathrm{b}}$ & $2.9(0.7)^{\mathrm{a}}$ \\
F-DLC & $419.7(43.3)^{\mathrm{b}}$ & $4.2(0.3)^{\mathrm{b}}$ \\
\hline
\end{tabular}

Data are expressed as means (SD).

Groups that do not share the same superscript letter are significantly different $(p<0.05)$.

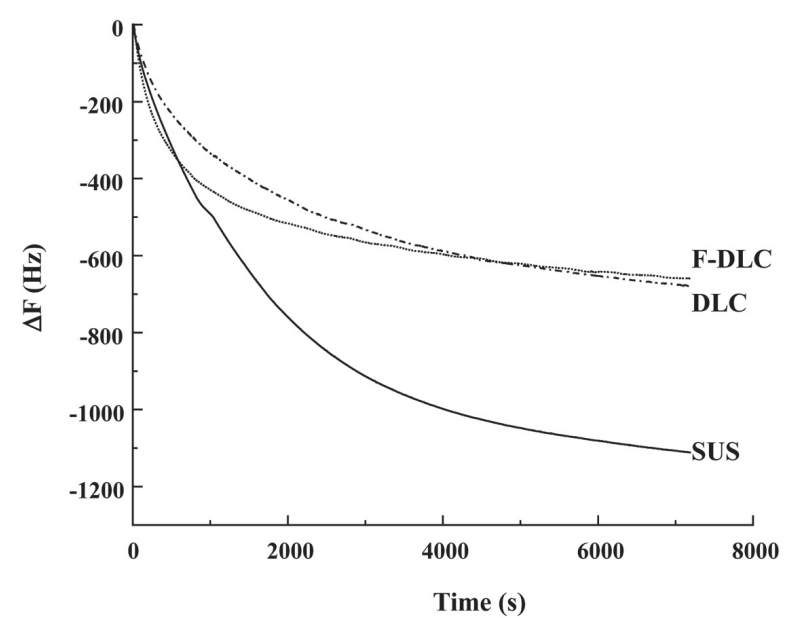

Fig. 2 Typical change in frequency for each sensor after protein injection.

amounts between DLC and F-DLC ( $p>0.05)$.

The apparent first-order reaction rate, $k_{\mathrm{obs}}$, indicates the albumin adsorption rate after injection. As shown in Table $5, k_{\text {obs }}$ of F-DLC was significantly larger than those of SUS and DLC $(p<0.05)$. However, there was no significant difference in $k_{\text {obs }}$ between SUS and DLC $(p>0.05)$.

\section{DISCUSSION}

In the present study, protein adsorption to SUS, DLC or F-DLC was evaluated by using the QCM method. We revealed that differences in materials influenced protein adsorption behaviors. DLC and F-DLC showed significantly smaller albumin absorbed amounts on their surfaces. Therefore, the null hypothesis - the different surfaces, namely, SUS, DLC and F-DLC, do not influence albumin adsorption- was rejected.

Ishihara et al. reported that the surface free energy of F-DLC is lower than that of DLC and antibacterial activity of DLC was improved by fluorine incorporation ${ }^{28)}$. In the present study, surface free energy also decreased in the order of SUS, DLC and F-DLC.

Hydrophobic interactions play an important role as a driving force in pellicle formation, and higher amounts of salivary proteins adsorb onto hydrophobic surfaces ${ }^{29)}$. Moreover, Wei et al. reported that albumin showed greater adsorption to hydrophobic surfaces ${ }^{30)}$. DLC and F-DLC have significantly hydrophobic surfaces. 


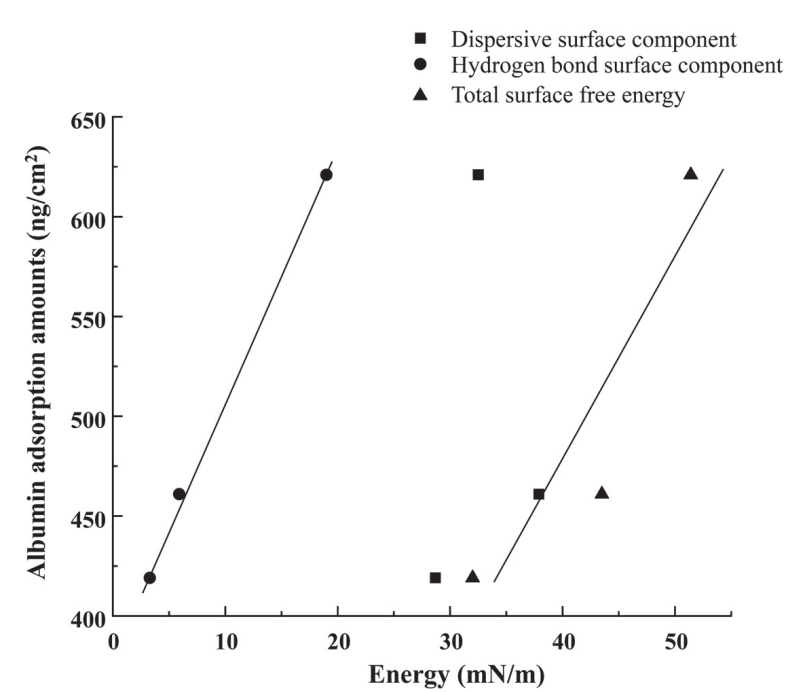

Fig. 3 Relationship between albumin absorbed amounts and total surface free energy, hydrogen bone component and dispersive surface component.

However, albumin absorbed amounts on DLC and F-DLC were significantly lower than that on SUS.

It is well known that the surface free energy of materials influences protein adsorption. In the present study, lower amounts of albumin adsorbed onto DLC and F-DLC, which had lower surface free energies. Baier and Dutton reported that minimum interaction between biomolecules and materials was obtained when the surface free energy of the material was $20-30 \mathrm{mN} / \mathrm{m}^{31}$. The total surface free energy of DLC and F-DLC is approximately $30-40 \mathrm{mN} / \mathrm{m}$. Therefore, the interaction between albumin and DLC or F-DLC is likely weak, resulting in decreased adsorption.

In this study, the relationship between surface free energy and albumin absorbed amounts was analyzed. As shown in Fig. 3, a positive correlation was found between total surface free energy and albumin absorbed amount, but the correlation was not linear $\left(r^{2}=0.83\right)$. However, a linear correlation was recognized between the hydrogen bond component and albumin absorbed amount $\left(\mathrm{r}^{2}=0.99\right)$. No correlation existed between the dispersive surface component and albumin absorbed amount. Michiardi et al. investigated the influence of surface free energy on protein adsorption on oxidized nickel-titanium alloy surfaces ${ }^{32}$. They found that surfaces with higher free energies produced higher amounts of albumin adsorption, and albumin adsorption was directly related to the surface energy with excellent linear correlation with the polar component of the surfaces studied. Our results correspond with their results. The surface of SUS is more hydrophilic than DLC and F-DLC. It is presumed that hydrophilic surface will easier to make hydrogen bond interaction with albumin compared to hydrophobic surface, although the clear reason is still under investigation. It is suggested that hydrogen bond interaction may contribute to albumin adsorption onto

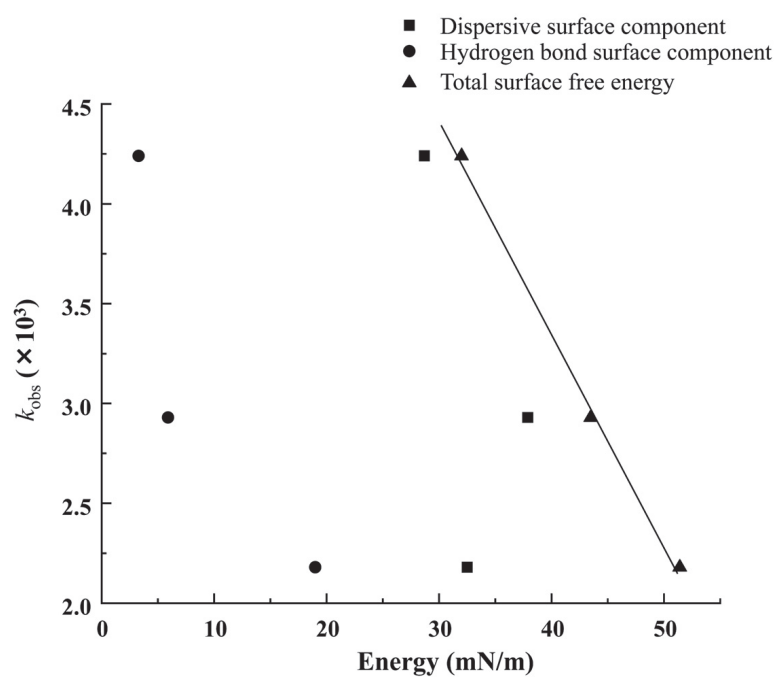

Fig. 4 Relationship between $k_{\text {obs }}$ and total surface free energy, hydrogen bone component and dispersive surface component.

the three different surfaces, SUS, DLC and F-DLC.

A larger value for $k_{\text {obs }}$ indicates a more rapid reaction rate, namely, more rapid albumin adsorption. We observed more rapid albumin adsorption onto F-DLC than DLC and SUS. The analysis of the correlation between $k_{\text {obs }}$ and surface free energy indicated a linear correlation existed between $k_{\mathrm{obs}}$ and total surface free energy $\left(r^{2}=0.99\right.$, Fig. 4$)$. In this case, a slightly linear correlation existed between $k_{\mathrm{obs}}$ and the hydrogen bond surface component $\left(\mathrm{r}^{2}=0.75\right)$, but not with the dispersive surface component $\left(r^{2}=0.30\right)$.

Surface roughness also affects protein adsorption ${ }^{33)}$. Generally, a roughened surface increases protein adsorption on the material surface. The smoother surface of DLC and F-DLC compared with SUS is one potential explanation for decreased albumin adsorption on their surfaces.

Various factors such as surface charges or chemical compositions also influence protein adsorption onto materials. Yoshida and Hayakawa ${ }^{21)}$ measured the apparent zeta potential of tested materials and speculated that lactoferrin adsorption onto titanium or zirconia was mainly influenced by electrostatic interaction. On the contrary, the concentration of albumin in oral saliva is generally estimated to be approximately $0.014-0.064$ $\mathrm{mg} / \mathrm{mL}^{34)}$. The concentration employed in our study is higher than that in oral saliva. It is suggested that the concentration of protein may also influence the adsorption behaviors of the protein. Further detailed analysis of protein adsorption is needed.

\section{CONCLUSIONS}

Albumin adsorption to SUS, DLC and F-DLC films was evaluated by using the QCM method. The adsorbed amounts of BSA on DLC and F-DLC were significantly 
lower than that on SUS. Furthermore, the apparent reaction rate, $k_{\mathrm{obs}}$, of F-DLC was significantly larger than those of SUS and DLC. Our results revealed that the significantly lower total surface free energies of DLC or F-DLC influenced albumin absorbed amounts and $k_{\text {obs. }}$. A clear correlation was found between albumin absorbed amounts and the hydrogen bond component of total surface free energy. Therefore, DLC or F-DLC coating is effective for preventing the protein adhesion on orthodontic appliances and may consequently decrease friction between the orthodontic wire and bracket due to the reduction of pellicle accumulation.

\section{ACKNOWLEDGMENTS}

This study was supported in part by a Grant-in-Aid for Research Activity start-up (16H07299) from the Japan Society for the Promotion of Science.

\section{REFERENCES}

1) Redlich M, Mayer Y, Harari D, Lewinstein I. In vitro study of frictional forces during sliding mechanics of "reduced-friction" brackets. Am J Orthod Dentofacial Orthop 2003; 124: 69-73.

2) Liu X, Ding P, Lin J. Effects of bracket design on critical contact angle. Angle Orthod 2013; 83: 877-884.

3) Kao CT, Guo JU, Huang TH. Comparison of friction force between corroded and noncorroded titanium nitride plating of metal brackets. Am J Orthod Dentofacial Orthop 2011; 139: 594-600.

4) Farronato G, Maijer R, Carìa MP, Esposito L, Alberzoni D, Cacciatore G. The effect of Teflon coating on the resistance to sliding of orthodontic archwires. Eur J Orthod 2012; 34: 410417.

5) Vetter J. 60 years of DLC coatings: Historical highlights and technical review of cathodic arc processes to synthesize various DLC types, and their evolution for industrial applications. Surf Coat Technol 2014; 257: 213-240.

6) Ohgoe $\mathrm{Y}$, Kobayashi S, Ozeki K, Aoki H, Nakamori H, Hirakuri K, Miyashita O. Reduction effect of nickel ion release on a diamond-like carbon film coated onto an orthodontic archwire. Thin Solid Films 2006; 497: 218-222.

7) Kobayashi S, Ohgoe Y, Ozeki K, Hirakuri K, Aoki H. Dissolution effect and cytotoxicity of diamond-like carbon coatings on orthodontic archwires. J Mater Sci Mater Med 2007; 18: 2263-2268.

8) Muguruma T, Iijima M, Brantley WA, Mizoguchi I. Effects of a diamond-like carbon coating on the frictional properties of orthodontic wires. Angle Orthod 2011; 81: 141-148.

9) Muguruma T, Iijima M, Brantley WA, Nakagaki S, Endo K, Mizoguchi I. Frictional and mechanical properties of diamondlike carbon-coated orthodontic brackets. Eur J Orthod 2013; 35: 216-222.

10) Akaike S, Hayakawa T, Kobayashi D, Aono Y, Hirata A, Hiratsuka M, Nakamura Y. Reduction in static friction by deposition of a homogeneous diamond-like carbon (DLC) coating on orthodontic brackets. Dent Mater J 2015; 34: 888895.

11) Akaike S, Kobayashi D, Aono Y, Hiratsuka M, Hirata A, Hayakawa T, Nakamura Y. Relationship between static friction and surface wettability of orthodontic brackets coated with diamond-like carbon (DLC), fluorine- or silicone-doped DLC coatings. Diam Relat Mater 2016; 61: 109-114.

12) Kusy RP, Whitley JQ. Resistance to sliding of orthodontic appliances in the dry and wet states: influence of archwire alloy, interbracket distance, and bracket engagement. J
Biomed Mater Res 2000; 52: 797-811.

13) Eliades T, Bourauel C. Intraoral aging of orthodontic materials: the picture we miss and its clinical relevance. Am J Orthod Dentofacial Orthop 2005; 127: 403-412.

14) Marques IS, Araújo AM, Gurgel JA, Normando D. Debris, roughness and friction of stainless steel archwires following clinical use. Angle Orthod 2010; 80: 521-527.

15) Normando D, de Araújo AM, Marques Ida S, Barroso Tavares Dias CG, Miguel JA. Archwire cleaning after intraoral ageing: the effects on debris, roughness, and friction. Eur J Orthod 2013; 35: 223-229.

16) Lamkin MS, Arancillo AA, Oppenheim FG. Temporal and compositional characteristics of salivary protein adsorption to hydroxyapatite. J Dent Res 1996; 75: 803-808.

17) Lendenmann U, Grogan J, Oppenheim FG. Saliva and dental pellicle: a review. Adv Dent Res 2000; 14: 22-28.

18) Martins MC, Sousa SR, Antunes JC, Barbosa MA. Protein adsorption characterization. Methods Mol Biol 2012; 811: 141-161.

19) Murray BS, Deshaires C. Monitoring protein fouling of metal surfaces via a quartz crystal microbalance. J Colloid Interface Sci 2000; 227: 32-41.

20) Yoshida E, Hayakawa T. Adsorption study of pellicle proteins to gold, silica and titanium by quartz crystal microbalance method. Dent Mater J 2013; 32: 883-887.

21) Yoshida E, Hayakawa T. Adsorption analysis of lactoferrin to titanium, stainless steel, zirconia, and polymethyl methacrylate using the quartz crystal microbalance method. BioMed Res Int 2016; 2016: 3961286.

22) Owens DK, Wendt RC. Estimation of the surface free energy of polymers. J Appl Polym Sci 1969; 13: 1741-1747.

23) Żenkiewicz M. Methods for the calculation of surface free energy of solids. J Achiev Mater Manuf Eng 2007; 24: 137145.

24) Morra M, Cassinelli C. Bacterial adhesion to polymer surfaces: a critical review of surface thermodynamic approaches. J Biomater Sci Polym Ed 1997; 9: 55-74.

25) Van Oss CJ, Ju L, Chaudhury MK, Good RJ. Estimation of the polar parameters of the surface tension of liquids by contact angle measurements on gels. J Colloid Interface Sci 1989; 128: 313-319.

26) Okahata Y, Kawase M, Niikura K, Ohtake F, Furusawa H, Ebara Y. Kinetic measurements of DNA hybridization on an oligonucleotide-immobilized $27-\mathrm{MHz}$ quartz crystal microbalance. Anal Chem 1998; 70: 1288-1291.

27) Sauerbrey G. The use of quartz crystal oscillators for weighing thin layers and for micro-weighing. Z Phys 1959; 155: 206222.

28) Ishihara M, Kosaka T, Nakamura T, Tsugawa K, Hasegawa M, Kokai F, Koga Y. Antibacterial activity of fluorine incorporated DLC films. Diam Relat Mater 2006; 15: 10111014.

29) Hannig C, Hannig M. The oral cavity -a key system to understand substratum-dependent bioadhesion on solid surfaces in man. Clin Oral Investig 2009; 13: 123-139.

30) Wei J, Igarashi T, Okumori N, Igarashi T, Maetani T, Liu B, Yoshinari M. Influence of surface wettability on competitive protein adsorption and initial attachment of osteoblasts. Biomed Mater 2009; 4: 045002.

31) Baier RE, Dutton RC. Initial events in interactions of blood with a foreign surface. J Biomed Mater Res 1969; 3: 191-206.

32) Michiardi A, Aparicio C, Ratner BD, Planell JA, Gil J. The influence of surface energy on competitive protein adsorption on oxidized NiTi surfaces. Biomaterials 2007; 28: 586-594.

33) Hannig M, Joiner A, The structure, function and properties of the acquired pellicle. Monogr Oral Sci 2006; 19: 29-64.

34) Hayakawa T, Suda T, Kizaki H, editor. Oral Biochemistry. 5th ed. Tokyo, Ishiyaku Publishers Inc., 2017. p. 195-202. 